S140 GDF-15 DOWN-REGULATION OF MUSCLE MICRORNA DRIVES INCREASED SENSITIVITY TO TGF- $\beta$ SIGNALLING; A NOVEL MECHANISM IN INTENSIVE CARE UNIT ACQUIRED WEAKNESS

${ }^{1}$ SAA Bloch, ${ }^{1} \mathrm{JY}$ Lee, ${ }^{2} \mathrm{~T}$ Syburrah, ${ }^{2} \mathrm{U}$ Rosendahl, ${ }^{1} \mathrm{PR}$ Kemp, ${ }^{2} \mathrm{MJD}$ Griffiths, ${ }^{2} \mathrm{MI}$ Polkey. ${ }^{1}$ Imperial College, London, UK; ${ }^{2}$ NIHR Respitatory BRU, Royal Brompton Hosptial London, UK

\subsection{6/thoraxjnl-2014-206260.146}

Introduction Intensive care unit acquired weakness (ICUAW) is common and associated with significant morbidity. We previously identified GDF-15, a TGF- $\beta$ super-family member, as a potential driver of acute muscle wasting in a novel human model of ICUAW (Crit Care Med 2013;2013;41:982). In the current study we investigated the potential mechanisms by which GDF15 may contribute to the development of ICUAW.

Dysregulation of muscle microRNAs has been described in muscle disorders. MicroRNAs are essential for muscle homeostasis and their expression can be influenced by inflammatory cytokines. Furthermore muscle microRNAs may down-regulate TGF$\beta$ signalling. However, the function of microRNAs in ICUAW has not previously been described. We hypothesised that downregulation of muscle microRNAs, driven by GDF-15, would lead to increased sensitivity to TGF- $\beta$ signalling in muscle of patients with ICUAW.

Methods We conducted an observational study of 20 patients with ICUAW and 7 elective surgical controls. Subjects underwent rectus femoris muscle biopsy and blood sampling. Muscle specimens were examined for mRNA and microRNA expression of target genes by qPCR. Plasma samples were tested for GDF-15 concentration (ELISA). Histology samples were stained for pSMAD2/3 nuclear positivity. To examine the effects of GDF-15 on target genes, differentiated $\mathrm{C} 2 \mathrm{C} 12$ myotubes were treated with GDF-15 for 4 days. The effect of over-expression of miR$181 \mathrm{a}$ in $\mathrm{C} 2 \mathrm{C} 12$ myoblasts on TGF- $\beta$ signalling was also examined.

Results Compared with controls, patients with ICUAW had greater GDF-15 mRNA expression in muscle (median 2-fold higher; $p=0.006$ ) and concentration in plasma (median 7239 vs. $2454 \mathrm{pg} / \mathrm{ml} ; \mathrm{p}=0.001)$. MicroRNAs involved in muscle homeostasis were significantly lower in muscle from patients with ICUAW. Both $\log [$ GDF-15 mRNA] and log[plasma GDF15] were significantly negatively correlated with $\log [$ microRNA expression]. GDF-15 treatment of myotubes significantly elevated expression of muscle atrophy-related genes and downregulated expression of muscle microRNAs. miR-181a suppressed TGF- $\beta$ responses in myoblasts, suggesting increased sensitivity to TGF- $\beta$ in ICUAW muscle. Consistent with this, nuclear phospho-SMAD2/3 and CYR61 mRNA expression were increased in ICUAW muscle.

Discussion By suppressing expression of muscle microRNAs GDF-15 may increase sensitivity to TGF- $\beta$ signalling, thus promoting muscle wasting in ICUAW. This study identifies both GDF-15 and associated microRNA as potential therapeutic targets in ICUAW.

\section{S141 TUMOUR NECROSIS FACTOR RECEPTOR 1 SHEDDING IS RELATED TO ACUTE SKELETAL MUSCLE WASTING IN CRITICAL ILLNESS}

${ }^{1}$ ZA Puthucheary, ${ }^{2}$ J Rawal, ${ }^{3} \mathrm{MJW}$ McPhail, ${ }^{3} \mathrm{~T}$ Dew, ${ }^{2} \mathrm{R}$ Phadke, ${ }^{4} \mathrm{~A}$ Rowlerson, ${ }^{4} \mathrm{SDR}$ Harridge, ${ }^{5} \mathrm{HE}$ Montgomery, ${ }^{6} \mathrm{~N}$ Hart. ${ }^{1}$ Division of Respiratory and Critical Care Medicine,
University Medicine Cluster, National University Health Systems, Singapore, Singapore; ${ }^{2}$ University College London, London, UK; ${ }^{3}$ Kings College Hospital NHS Foundation Trust, London, UK; ${ }^{4}$ Centre of Human and Aerospace Physiological Sciences, King's College London, London, UK; ${ }^{5}$ Institute of Health and Human Performance, University College London, London, UK; ${ }^{6}$ Lane Fox Clinical Respiratory Physiology Unit, Guy's and St Thomas' NHS Foundation Trust, London, UK

\subsection{6/thoraxinl-2014-206260.147}

Introduction Muscle wasting occurs early and rapidly in critically ill patients. It results from a decrease in muscle protein synthesis and an increase in its breakdown, with muscle necrosis a common associated finding. The drivers for such atrophy and necrosis remain poorly understood, as do the related regulatory pathways. We hypothesised that systemic and intracellular cytokines play a role in this process.

Methods The UK-MUSCLE study prospectively studied the wasting response (change in Rectus Femoris cross sectional area $\left(\mathrm{RF}_{\mathrm{CSA}}\right)$ using serial ultrasound) in critically ill patients admitted to the ICU. Cytokine profiles (high sensitivity cytokine chip array, Randox, Ireland) were analysed in serum samples from 62 of these patients (days 1 and 7) and in contemporaneous Vastus Lateralis biopsies of 35 patients. Tumour Necrosis Factor (TNF)$\alpha$, TNF receptor (TNFR) 1 and 2, interleukin (IL)1a, il1b, IL-2, IL-4, IL-6, IL-8, IL-10, Vascular Endothelial growth Factor (VEGF), Interferon (IFN)- $\gamma$, Monocyte Chemoattractant Protein1(MCP-1) and Epidermal Growth Factor were assayed. Muscle necrosis was determined by hematoxylin and eosin staining of the Vastus Lateralis biopsies.

Results Intramuscular TNFR1 concentrations increased over 7 days $(0.83 \pm 1.1 \mu \mathrm{g} / \mathrm{L}$ to $2.07 \pm 2.65 \mu \mathrm{g} / \mathrm{L} ; \mathrm{p}=0.042)$, as $\operatorname{did}$ intramuscular interleukin-10 $(22.69 \pm 26.5 \mathrm{ng} / \mathrm{L}$ to $59.8 \pm 80.0$ $\mathrm{ng} / \mathrm{L} ; \mathrm{p}=0.005)$. Increases in serum IL-1a $(0.52 \pm 0.26 \mathrm{ng} / \mathrm{L}$ to $0.57 \pm 0.28 \mathrm{ng} / \mathrm{L}, \mathrm{p}=0.03), \operatorname{VEGF}(166.86 \pm 231.7 \mathrm{ng} / \mathrm{L}$ to $246.6 \pm 236.7 \mathrm{ng} / \mathrm{L}, \mathrm{p}<0.001)$ and MCP-1 (886.8 $\pm 685.0 \mathrm{ng} /$ $\mathrm{L}$ to $386.49 \pm 469.7 \mathrm{ng} / \mathrm{L}, \mathrm{p}<0.001)$ were seen as well as a decrease in IL-6 $(322.2 \pm 422.7 \mathrm{ng} / \mathrm{L}$ to $78.55 \pm 184.4 \mathrm{ng} / \mathrm{L}$, $\mathrm{p}<0.001)$, il-10 $(22.73 \pm 51.1 \mathrm{ng} / \mathrm{L}$ to $7.61 \pm 15.3 \mathrm{ng} / \mathrm{L}$, $\mathrm{p}=0.03)$, IFN- $\gamma(4.76 \pm 11.0 \mathrm{ng} / \mathrm{L}$ to $1.28 \pm 2.02 \mathrm{ng} / \mathrm{L}$, $\mathrm{p}=0.02)$ and MCP-1 $(886.8 \pm 685.0 \mathrm{ng} / \mathrm{L}$ to $386.49 \pm 469.7$ $\mathrm{ng} / \mathrm{L}, \mathrm{p}<0.001)$. Neither myonecrosis nor change in $\mathrm{RF}_{\mathrm{CSA}}$ was related to that in intramuscular cytokines by linear and logisticalregression analysis, using $10 \%$ loss as a cut off. Loss in $\mathrm{RF}_{\mathrm{CSA}}$ over 10 days was very weakly correlated with serum TNFR1 concentration on days $1\left(\mathrm{r}^{2}=0.12 ; \mathrm{p}<0.01\right)$ and $7\left(\mathrm{r}^{2}=0.09\right.$; $\mathrm{p}=0.02)$ and with serum IL-10 concentration $\left(\mathrm{r}^{2}=0.19\right.$; $\mathrm{p}<0.01)$. Myofibre necrosis was unrelated to serum cytokine profile.

Discussion Soluble TNFR1 is associated with the degree of muscle wasting in critical illness. This relationship may be causal as TNF1R signalling leads to activation of nuclear factor kappa beta and apoptosis. Whilst no evidence was seen for intramuscular inflammation, increased intramuscular IL-10 may be protective, in its anti-inflammatory role.

\section{S142 VASTUS LATERALIS PROTEOMIC ANALYSIS IN MUSCLE WASTED PATIENTS WITH COPD USING TWO-DIMENSIONAL FLUORESCENT ELECTROPHORESIS}

${ }^{1}$ Roberto A Rabinovich, ${ }^{1}$ Ramzi Lahkdar, ${ }^{1}$ Ellen M Drost, ${ }^{2}$ Ricardo Bastos, ${ }^{1}$ William MacNee. ${ }^{1}$ ELEGI Colt Laboratory, Centre for Inflammation ResearchThe Queen's Medical Research Institute, University of Edinburgh. Scotland, Edinburgh, UK; ${ }^{2}$ IDIBAPS, University of Barcelona, Barcelona, Spain

10.1136/thoraxjnl-2014-206260.148 